\title{
Operative Cholangiography. Its Effect on the Practice of Cholecystectomy
}

\author{
M. H. WHEELER, ${ }^{*}$ M.B., CH.B., F.R.C.S. ; SOMPONG RAKSASOOK, $\dagger$ M.D., F.R.C.s.I.
}

\author{
J. ALEXANDER WILLIAMS, $\ddagger$ M.D., CH.M., F.R.C.S.
}

British Medical fournal, 1970, 4, 161-164

Cholecystectomy is second only to appendicectomy as the most commonly performed abdominal operation. ${ }^{1}$ Consequently it is not surprising that there have been many studies of large series of patients undergoing this procedure ${ }^{23}$ Surgery of the common bile duct has received almost as much attention in published work, with the indications for duct exploration being at the centre of the discussion. ${ }^{45}$ Most authors agree that the clinical indications for choledochoromy are a history of jaundice, colic, rigors, or pancreatitis, and the operative findings paloable choledochal stones, a dilated or thickened common duct, or multiple small stones in the gall bladd ${ }^{\circ} r$. It is generally accep ${ }^{+}$d, however, that when the decision whether or not to perform choledochotomy is based on clinical grounds alone there is a $10 \%$ incidence of residual stones and a $50 \%$ incidence of fruitless choledochotomy. ${ }^{67}$ Choledochotomy when added to cholecystectomv triples the mortality rate, whether or not stones are found. ${ }^{8}$ Obviously, therefore, fruitless choledochotomy should be avoided whenever possible.

Since the introduction of operative cholangiography in 1931 by Mirizzi it has become andarent that this techniaue might help to reduce the morbidity and mortality associated with cholecystectomy and choledochotomy both by preventing the presence of choledochal stones being overlooked and by reducing the necessity to open the duct when there were no stones. ${ }^{9}$ Some authorities believe, however, that operative cholangiography should never become a substitute for clinical appraisal, and a negative cholangiogram should not deter one from opening the duct if there is a sound clinical reason. ${ }^{10}$

Two series of patients undergoing cholecystectomy in the United Birmingham Hospitals are compared in this report. The first group were operated on between 1955 and 1959, at a time when operative cholangiography was used infrequently, and the second between 1960 and 1970 when this technique was being performed in most cases. The results are analysed in an attempt to evaluate the effects of operative cholangiography on the incidence of fruitless choledochotomy-that is, choledochotomy with no stones and no duct abnormalityand the proportion of cases in which stones are found. The complications of fruitless choledochotomy, the incidence of reoperation, and the causes of death in the series are also assessed.

\section{Patients}

The first group of 1,008 patients (group 1) was operated on between 1955 and 1959 by 18 different surgical firms, the number of operations per surgeon per year varying from 1 to

\footnotetext{
* Research Registrar, United Cardiff Hospitals.

† Surgical Specialist, Bangkok, Thailand.

Consultant Surgeon, United Birmingham Hospitals, External Scientific Staff, Medical Research Council.
}

Requests for reprints to J.A.W., The General Hospital, Birmingham, B46NH.
20. The second group of 201 patients (group 2) was operated on during a 10-year period by one surgical firm.

In group (1) operative cholangiography was performed only 37 times $(3.6 \%)$ while in group (2) the technique was employed on 173 occasions $(86.5 \%)$. In both groups about half the operations were performed by consultants, while the other half were performed by registrars in training. The most frequent indication for operation in both groups was chronic cholecystitis. Only a few were operated on during an acute exacerbation. Other indications included operations for unexplained jaundice or the chance finding of gallstones on $x$ ray examination or at laparotomy.

In group 1 the mean age for women was 53.3 years and for the men 55.6 years, while in group 2 the mean ages were a little younger, being 49.8 years and 52.5 years, respectively.

\section{Results}

\section{Incidence of Fruitless Choledochotomy}

Group 1.-Choledochotomy was indicated clinically by one or more of the defined criteria in 555 cases (59\% of the total), but was performed in only 283 cases $(28.4 \%$ of the total). It must be presumed therefore that a decision was made not to explore the common bile duct in 272 patients despite indications to do so. Of the 283 patients undergoing choledochotomy stones were found in only $118(41.7 \%$ of those explored). Therefore no fewer than $165(58.3 \%)$ patients had a fruitless choledochotomy, the duct being explored but no abnormality found.

A history of jaundice or colic and the operative finding of a common bile duct that was judged to be dilated led to the finding of common duct stones in less than half the patients in whom these indications were present (Table I). The finding of a palpable common duct stone was, as might be expected, a good indication of the presence of a stone. Four patients with chronic pancreatitis, however, were thought to have palpable stones and yet nothing abnormal was found on exploration.

Group 2.-Operative cholangiography was used in most of this smaller group of 201 patients. Though clinical indications for choledochotomy were carefully considered, probably the cholangiogram findings were the most important factor in deciding whether or not to explore. One or more clinical indications were present in $119(59.5 \%$ of the total), slightly more than in group 1 , yet choledochotomy was performed in fewer -47 patients $(23.5 \%)$. Stones were found in $34(72 \%)$ of patients undergoing choledochotomy; only $13(28 \%)$ had a fruitless exploration. In the small group in whom ductal stones were palpated there was $100 \%$ positive exploration rate. When the other clinical indications were present the positive exploration rate varied between 78 and $84 \%$ (Table I).

TABLE I.-Indications for Performing a Choledochotomy in Groups 1 and 2

\begin{tabular}{|c|c|c|c|c|c|c|c|c|c|c|c|c|c|c|c|c|}
\hline \multicolumn{8}{|c|}{ Group 1} & \multicolumn{9}{|c|}{ Group 2} \\
\hline \multirow{2}{*}{ Indications } & \multicolumn{2}{|c|}{ Cases } & \multicolumn{2}{|c|}{ Duct Explored } & \multicolumn{3}{|c|}{ Finding of Stones } & \multirow{2}{*}{$\begin{array}{l}\% \text { Positive } \\
\text { Exploration }\end{array}$} & \multicolumn{2}{|c|}{ Cases } & \multicolumn{2}{|c|}{ Duct Explored } & \multicolumn{3}{|c|}{ Finding of Stones } & \multirow{2}{*}{$\begin{array}{l}\% \text { Positive } \\
\text { Exploration }\end{array}$} \\
\hline & No. & $\begin{array}{c}\% \\
\text { Whole } \\
\end{array}$ & No. & $\begin{array}{c}\% \\
\text { Group } \\
\end{array}$ & No. & $\begin{array}{c}\% \\
\text { Group } \\
\end{array}$ & $\begin{array}{c}\% \\
\text { whole } \\
\end{array}$ & & No. & $\begin{array}{c}\% \\
\text { whole }\end{array}$ & No. & $\begin{array}{c}\% \% \\
\text { Group }\end{array}$ & No. & $\begin{array}{c}\% \\
\text { Group }\end{array}$ & $\begin{array}{c}\% \% \\
\text { whole }\end{array}$ & \\
\hline $\begin{array}{l}\text { History of Jaundice } \\
\text { History of Colic } \\
\text { Palpable Common Bile }\end{array}$ & $\begin{array}{l}327 \\
287\end{array}$ & $\begin{array}{l}32 \\
28\end{array}$ & $\begin{array}{l}206 \\
104\end{array}$ & $\begin{array}{l}63 \\
36\end{array}$ & $\begin{array}{l}97 \\
52\end{array}$ & $\begin{array}{l}30 \\
18\end{array}$ & $\begin{array}{l}9 \cdot 6 \\
5 \cdot 1\end{array}$ & $\begin{array}{l}47 \cdot 1 \\
50\end{array}$ & $\begin{array}{l}62 \\
84\end{array}$ & $\begin{array}{l}31 \\
42\end{array}$ & $\begin{array}{l}27 \\
21\end{array}$ & $\begin{array}{c}43.5 \\
25\end{array}$ & $\begin{array}{l}21 \\
19\end{array}$ & $\begin{array}{r}34 \\
22 \cdot 6\end{array}$ & $\begin{array}{r}10.5 \\
9.5\end{array}$ & $\begin{array}{l}78 \\
90\end{array}$ \\
\hline $\begin{array}{l}\text { Duct Stone } \\
\text { Dilated Common Bile }\end{array}$ & 60 & 6 & 60 & 100 & 56 & 93 & $5 \cdot 5$ & $90 \cdot 3$ & 12 & 6 & 12 & 100 & 12 & 100 & 6 & 100 \\
\hline $\begin{array}{l}\text { Duct } \\
\text { Jaundice and "Dilated }\end{array}$ & 171 & 16.9 & 144 & 84 & 64 & 37.5 & $6 \cdot 3$ & $44 \cdot 4$ & 23 & $11 \cdot 5$ & 18 & 78 & 17 & 74 & 8.5 & 94 \\
\hline Duct .. & 118 & $11 \cdot 7$ & 106 & 91 & 53 & 45 & $5 \cdot 2$ & 50 & 14 & 7 & 13 & 93 & 12 & 86 & 6 & 93 \\
\hline
\end{tabular}




\section{Follow-up}

Of the 72 patients in this series in whom there were clinical indications for choledochotomy, and yet the duct was not explored because of normal cholangiographic findings, 67 (93\%) have been followed up from six months to eight years, mean follow-up being 5.5 years. The follow-up examination has included a questionnaire and biochemical screening tests. In no patient has there been any evidence of residual bile duct stones.

\section{Incidence of Bile Duct Stones}

Group ' 1 '.-Stones were found in the bile ducts of 118 (11.7\%) of the 1,008 patients.

Group ' 2 '.-Stones were found in $34(17 \%)$ of the 201 patients in this series. There was a significantly higher yield of stones in the second series in which operative cholangiography was performed $\left(\chi^{2}=4.4 P<0.05\right)$.

\section{Risks of Fruitless Choledochotomy}

As there were only 13 patients with fruitless choledochotomy in group 2 this group cannot be analysed separately. As the potential risks in opening a common bile duct but finding no abnormality are the same in both series the groups have been analysed together and the results are shown in Table II.

TABle II.-Incidence of Complications Occurring in 178 Patients Submitted to Fruitless Choledochotomy in Groups 1 and 2

\begin{tabular}{|c|c|c|c|c|c|c|}
\hline \multicolumn{3}{|l|}{ Complications } & \multicolumn{2}{|c|}{$\begin{array}{l}\text { Duct Explored } \\
\text { No Stones Found }\end{array}$} & \multicolumn{2}{|c|}{$\begin{array}{l}\text { Duct Not Explored } \\
\text { No Indications } \\
525 \text { patients }\end{array}$} \\
\hline & & & No. & $\%$ & No. & $\%$ \\
\hline $\begin{array}{l}\text { Death } \quad . . \\
\text { Bile Leak . } \\
\text { Wound Infection } \\
\text { Respiratory Infection } \\
\text { Thrombotic (Not fatal) } \\
\text { Them }\end{array}$ & $\begin{array}{l}\cdots \\
\cdots \\
\cdots\end{array}$ & $\begin{array}{l}\ldots \\
\cdots \\
\cdots\end{array}$ & $\begin{array}{r}7 \\
12 \\
12 \\
17 \\
5\end{array}$ & $\begin{array}{l}3 \cdot 9 \\
6 \cdot 7 \\
6 \cdot 7 \\
9 \cdot 5 \\
2 \cdot 8\end{array}$ & $\begin{array}{r}9 \\
5 \\
31 \\
68 \\
31\end{array}$ & $\begin{array}{r}1 \cdot 7 \\
0.9 \\
5.9 \\
13.0 \\
5.9\end{array}$ \\
\hline Total & . & $\ldots$ & 53 & 30 & 144 & 27 \\
\hline
\end{tabular}

The complications in 178 patients with fruitless choledochotomy are compared with those in 525 patients in whom there was no indication for choledochotomy and the duct was not explored, although these are not strictly comparable groups. The mean ages of the two groups were, however, comparable, being 54.7 years and 54.4 years, respectively. Though there was no significant difference in the overall complication rate, death and leakage of bile were more common in the patients having a fruitless choledochotomy (Table II). The risk of death was twice as great in those patients who had the common duct explored, though this difference was not statistically significant $(P>0.05)$.

The risk of complication of biliary leak is, as might be expected, seven times as great in the group of patients having their common duct explored fruitlessly $(\mathrm{P}<\cdot 001)$. Wound and respiratory infection show no significant difference between the two groups. The risk of a non-fatal thrombotic complication was twice as high in the patients who did not have their duct explored. It was difficult to determine the exact significance of this finding, particularly in view of the well-known inaccuracy of clinical indications of deep venous thrombosis. The inaccuracy of clinical information is, however, comparable in both groups, and possibly some factor related to the past history of jaundice might have protected those patients who had a fruitless choledochotomy from venous thrombosis.

\section{Reoperations}

Group 1.-In this group there were $53(5.3 \%)$ second operations within one year of the cholecystectomy (Table III). Twenty-seven patients were operated on for missed
TABLE III.-Reasons for Reoperations in Groups 1 and 2

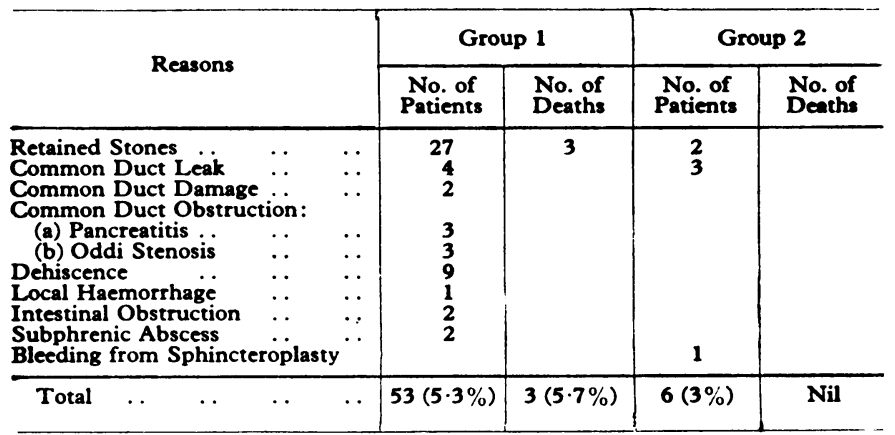

stone. In seven the common bile duct was not explored at the first operation, in eight no stones were found the first time, and in 10 stones were initially incompletely removed. Two patients were subjected to fruitless reexploration on false $T$ tube cholangiogram findings. In 20 cases if an operative cholangiogram had been performed the need for reoperation may have been avoided. Operative cholangiography performed in one case, however, was misleading owing to a technical error of too much dye being injected. Possibly an operative $T$ tube cholangiogram or choledochoscopy could have demonstrated retained stones in 12 patients and so have prevented reoperation.

The three $(5.7 \%)$ deaths which occurred in reoperations all occurred when the surgery was for missed stones. The second commonest cause for repeat surgery was wound dehiscence (nine cases), while common duct leakage was the cause for reoperation in only four cases.

Group 2.-Six (3\%) patients were submitted to reoperation within the first year, retained stones being the cause in two cases (Table III). In neither of these patients was operative $T$ tube cholangiography or choledochoscopy carried out after choledochotomy, though operative cholangiography via the cystic duct had been performed. Bleeding from the site of a sphincteroplasty accounted for one reoperation and biliary leak for the remaining three. One of the patients with a biliary leak did not have her common duct explored. At reoperation the cystic duct stamp was intact, and it was presumed that the biliary leak had taken place from the gall bladder bed. There were no deaths in the group of six reoperations.

\section{Deaths}

Deaths in group 1 were sub-divided into two categories, (a) "avoidable" and (b) "unavoidable," in terms of the possible importance of either missed bile duct stones or the complications of duct exploration (Table IV).

TABLE IV.-Avoidable and Unavoidable Causes of Death in Group 1

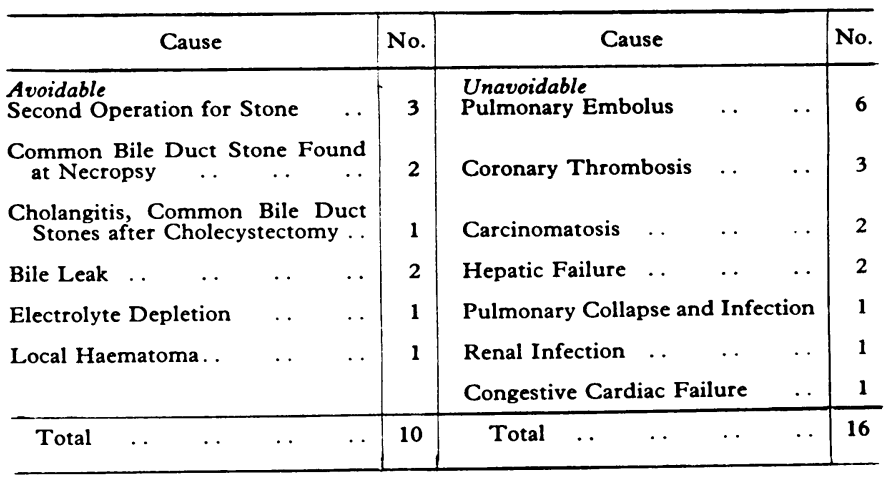

Avoidable Deaths. - The one death from electrolyte depletion could have been avoided with more attention to postoperative care, though a major factor was excessive biliary drainage following a fruitless choledochotomy and dilatation of the sphincter of Oddi. With the exception of the patient 
who died from a sub-hepatic haematoma and the one following a biliary leak from a duodenotomy, all the deaths in this group might possibly have been avoided if operative cholangiography had been carried out, and so eliminated the need for reexploration and fruitless duct exploration.

Unavoidable Deaths.-There were 16 deaths in this category, the commonest cause being pulmonary embolus. Two patients were found to have carcinomatosis, one from a primary tumour in the gall bladder, and the other the stomach. It is perhaps surprising that in a series of over 1,000 cholecystectomies only one carcinoma of the gall bladder should be found. The total of 26 deaths represents a death rate overall of $2.58 \%$, with 23 of the deaths occurring in patients over the age of 55 years.

Three deaths occurred in group 2-that is, $1.5 \%$ of the whole series; two patients were over 55 years of age. The patient who died of pulmonary oedema following a possible myocardial infarction had been submitted to unnecessary choledochotomy, no operative cholangiography being carried out. The patient dying of biliary peritonitis was 82 years old, and also had an undetected carcinoma of the stomach. He did not have the common duct explored and the small bile leak came from the liver bed.

\section{Failed Cholangiography}

In group 2173 patients had cholangiography. Of the remaining 28 patients, 23 were in the first two years of the series before the technique became a routine. Of the 173 cholangiograms 166 gave the correct diagnosis as judged by the findings of stones on choledochotomy or the satisfactory follow-up record of the patients. In seven the findings were misleading, five could be classified as false positive findings and two false negative.

False Positives.-In one patient the presence of multiple air bubbles was erroneously interpreted as stones. In two patients the radiologist thought that stones might possibly be present but none were found, and in another two the radiologist considered that the poor quality of the films prevented interpretation, so the ducts were opened but no stones found. Four of these five false positive reports occurred in the first half of the series and could have been prevented by attention to technique.

False Negatives.-In both patients the quality of the films was poor owing to poor technique. In one instance quite clearly the radiologist and the surgeon erroneously interpreted as normal films which showed on review both dilatation of the duct $(11 \mathrm{~mm}$.) and a distal filling defect. A stone was palpated by the surgeon and removed. In the second patient the ducts contained too much dye and the stones were obscured. The duct, however, was dilated and the surgeon explored on suspicion and removed stones. In both patients there were stones left in the duct at operation which were removed at second exploration.

\section{Cholangiographic Successes}

In three patients ( $1.5 \%$ of group) there were no clinical indications for choledochotomy, the ducts were not dilated, and no stones were palpated. Stones were demonstrated on cholangiography and successfully removed from the ducts.

\section{Discussion}

There are obvious limitations in comparing two sequential series as improvements in anaesthesia and case management will always tend to favour the second series. Some of the obvious apparent advantages of operative cholangiography, however, did not seem to justify a controlled trial, and our results are presented without apology and are presented in part as an audit of our own technique of cholangiography, which is still far from perfect, using as we do makeshift equipment. The fact that half the entire series of operations was performed by registrars in training is an indication of what is achieved in ordinary practice and not of what could be achieved by skilled experts using ideal equipment.

Within these limitations certain conclusions can be drawn. Clearly from the results of the early series (group 1) not all surgeons obey the clinical rules and perform choledochotomy whenever there is a history of jaundice or colic or whenever they assess the common duct as being dilated. Furthermore, even when they do open the ducts for these indications, their chances of finding a stone will be a little under half.

From the latter series (group 2) it appears that if surgeons rely on cholangiographic findings only they will be correct in $96 \%$ of cases (166 of 173 in this series) and that with experience and attention to technique this should approach $100 \%$. We do not agree with Hoerr that clinical indications should always take preference over cholangiographic findings, with the obvious exception of the findings of palpable stones in the common duct. ${ }^{10}$ We agree with Chapman, Curry, and Le Quesne that a normal operative cholangiogram can be relied on as evidence that the duct is free of stones. ${ }^{11}$ Moreover, the significantly higher yield of stones in the second group is more likely to be due to the success of cholangiography than any inherent difference in the groups. A possible explanation for the difference of $6 \%$ between the stone yield in the two groups $(11.7 \%$ and $17 \%$, respectively) being higher than the $1.5 \%$ "cholangiography success" rate of the second series is that many stones have been left behind in the first series. For example in group 1, 327 patients gave a history of jaundice, yet only $206(63 \%$ of these) had the duct explored. Stones may have been missed in the remainder.

The evidence of the dangers of fruitless choledochotomy is not very significant in this series with the exception of the complication of bile leakage. Nevertheless, there are undoubted advantages in sparing patients an unnecessary choledochotomy and no intrinsic therapeutic advantage in exploring a normal duct.

Hicken and McAllister reported a $20 \%$ incidence of retained common duct stones in a series of 550 patients submitted to cholecystectomy. ${ }^{12}$ No less than $81 \%$ of their 110 patients with retained stones required second operations. In our series second operations were necessary in 53 patients $(5.3 \%)$ in group 1 and six $(3 \%)$ in group 2, retained stones being responsible in 27 cases and two cases in groups 1 and 2, respectively. Operative cholangiography can reduce the incidence of missed stones, and in group 1 probably this technique could have helped in 20 of the 27 cases reoperated on.

Post-choledochotomy $T$ tube cholangiography, and/or choledochoscopy done on the operating table is of unquestionable value, particularly in avoiding incomplete' removal of stones from the common duct. These techniques were not used universally even in group 2 when they might have prevented two of the reoperations.

The overall death rate for operations on the gall bladder and biliary tree is generally reported to be between 1.5 and $2 \%{ }^{1314}$ but this figure rises in patients over 50 years of age. ${ }^{2}$ In these two groups the mortality was 2.58 and $1.5 \%$, respectively. In the over-55-year-olds it was 4.6 and $2 \%$, respectively, and under 55 years 0.6 and $1 \%$, respectively. Reoperation for residual stones may carry a mortality rate of as high as $9 \% .15$ In group 1 the three deaths occurred in those patients who had residual stones, thus resulting in a death rate of $5.7 \%$. The mortality rate for patients undergoing common duct exploration in group 1 was $3.9 \%$ and in group 2 $2 \cdot 1 \%$.

From a study of these two groups of patients it is concluded that operative cholangiography is an invaluable adjunct in biliary surgery. Its use should not be restricted to the occasional case but should be employed routinely. 
REFERENCES

1 Colcock, B. P., McManus, J. E. (1955). Surgery, Gynecology and Obstetrics,

101, 161.
Glenn, F. (1959). Surgery, Gynecology and Obstetrics, 109, 591.

Colcock, B. P., Perey B. (1963). Surgery, Gynecology and Obstetrics, 117, 529.

4 Bartlett, M. K., Waddell, W. R. (1958). New England fournal of Medicine, 258, 164.

s Mixter, C. C., Hermanson, L., Segel, A. L. (1951). Annals of Surgery, 134, 346.

- Acosta, J. M., Fotheringham, W. T., Ruiz L. O., Nardi G. L. (1969). Archives of Surgery, 99, 29.

? Hight, D., Lingley, J. R., Hurtubise, F. (1959). Annals of Surgery, 1959,
$150,1086$.

8 Harvard, C. (1960). Annals of the Royal College of Surgeons of England, 26, 88 .

Walters, W. (1955). Archives of Surgery, 70, 323

10 Hoerr, S. O. (1954). Archives of Surgery, 69, 432

1 Chapman, M., Curry, R. C., Le Quesne, L. P. (1964). British fournal of Surgery, 51, 600 .

12 Hicken, N. F., McAllister, A. J., Call, D. W. (1954). Archives of Surgery, $68,643$.

13 Glenn, F., and McSherry, C. K. (1963). Annals of Surgery, 157, 695

14 Marshall, J. F. (1958). American fournal of Surgery, 95, 845.

15 Thomson, F. B. (1956). Surgery, Gynecology and Obstetrics, 103, 78.

\section{ANY QUESTIONS?}

\section{We publish below a selection of questions and answers of general interest.}

\section{Treatment of Spastic Colon}

Q.-What drugs and dietary regimen should be followed in a case of spastic colon?

A.-As this condition is of unknown aetiology, and indeed may contain several entities, there is no specific treatment. Furthermore, the symptoms may vary considerably so treatment is tailored to the individual patient. The best dietetic advice is for the patient to avoid any foods that are known to cause symptoms as long as the intake is balanced; there is no place for a low-residue diet. Very occasional cases may have symptoms from alactasia and benefit from milk restriction.

Diarrhoea can be controlled by codeine phosphate $15-30 \mathrm{mg}$. two or three times a day. Diphenoxylate hydrochloride (Lomotil) is also useful. Constipation, and sometimes diarrhoea, is best treated with such bulkincreasing preparations as Isogel or Normacol; some doctors prefer to use bran. Antispasmodics and tranquillizers are sometimes used, but there is little evidence that their role is more than a placebo. Psychological factors are common but can usually be handled by a sympathetic physician. Depression should be recognized and treated.

\section{Sensitivity to Imipramine}

Q.-Once photosensitivity to imipramine has developed does it persist, and can anything be done to prevent it?

A.-Phototaxic and photoallergic reactions are well known to occur with chlorpromazine, but, so far as I am aware, no established case has been reported with imipramine.

\section{Source of Ejaculate Fluid}

Q.-What is the main source of ejaculate fluid? Is the bulk of it secreted by the prostate or by the seminal vesicles?

A.-The fluid portion of the human ejaculate-i.e., so-called seminal plasma-is composed of the secretory fluids produced in the various accessory organs of reproduction. According to Lundquist $^{1}$ the prostatic secretion contributes normally $12.8-32.5 \%$ of seminal plasma; the seminal vesicle secretion $46.3-80.4 \%$; and the combined testis-epididymis secretions only 1.6$12 \cdot 9 \%$.
At present two chemical indicators are used most frequently for assessing the secretory function of the prostate and seminal vesicles. They are based on determinations of citric acid and fructose respectively. ${ }^{2}$

\section{References \\ Lundouist, F., $A c^{\prime} a$ Physiologica Scandinavica 1949, 19, Supp. No. 66. \\ Mann, $\mathrm{T}_{.,}$Biochemistry of Semen and of the Male Reproductive Tract. London, Methuen,
1964 .}

\section{Snake Venoms}

Q.-What is the toxic component of snake venom and is it chemicaliy related to the cyanides?

A.-Snake venoms are a complex mixture chiefly of proteins, some of which have enzyme activity. However, the lethal fractions of venoms seem to be more closely related to the nonenzymatic protein portions than to the enzymes, though the enzymes may contribute to toxicity. In addition, the envenomed victim may release autopharmacological substances (and this makes the study of modes of actions of venoms even more difficult).

The harmful effects of snake venoms are directed principally against the cardiovascular and blood systems, nervous system, and the respiratory system. ${ }^{1}$

Cyanide is not chemically related to snake venoms. Cyanide reacts with the trivalent iron of cytochrome oxidase to form the cytochrome oxidase- $\mathrm{CN}$ complex. Cellular respiration is thus inhibited and cyanide produces a cytotoxic hypoxia. ${ }^{2}$

\section{REFERENCES}

1 Russell, F. E., Federation Proceedings, 1967, 26 1206 . F. E., Federation Proceedings, 1967,26 ,
Swinyard E. An The Pharmacological Basis of
Therapeutics, 1965, 3rd edn. ed. L. S. Good. Therapeutics, 1965 , 3rd. edn., ed. L. S. Goo

\section{Anaesthesia in Non-Europeans}

Q.-What special investigations need to be made, or special precautions taken, before administering a general anaesthetic to a non-European child prior to dental extraction?

A.- The hazards of general anaesthesia in non-European races arise partly because of their liability to certain hereditary and acquired diseases not common in Europe, partly because of skin pigmentation which renders the detection of cyanosis difficult The problem is intensified by the prevalence of iron-deficiency anaemia in areas where dietary intake is inadequate and infection with intestinal parasites is common.

Of the hereditary disease sickle-cell disease is probably of most concern to anaesthetists. Abnormal haemoglobin ( $\mathrm{HbS}$ ), present as the exclusive form in the homozygous (SS) sickle-cell anaemia, causes recurrent episodes of haemolysis, infarctive phenomena resulting from intravascular thrombosis, and occasionally bone-marrow aplasia. Attacks are precipitated by lowered oxygen tension, pyrexia, infection, dehydration, acidosis, and hypotension. Anaesthesia in patients suffering from this disease frequently precipitates an exacerbation. The heterozygous form (sickle-cell trait SA) is rarely associated with a suggestive clinical history and anaesthesia does not commonly give rise to undue hazard. Porphyria, though sometimes thought to be common in non-Europeans, appears to be most prevalent in peoples of Scandinavian, Anglo-Saxon, Dutch, and Germanic descent.

Tropical diseases are generally of little significance in dental anaesthesia except when they result in anaemia, general debility, or hepatic or renal damage. A few, however, deserve special mention. Schistosomiasis, endemic in the Far East, may involve the lungs to such an extent as to produce severe pulmonary hypertension. Tuberculosis is common in many countries, and any patient with a history of chronic chest disease should have a preoperative chest $x$-ray.

Emetine therapy for amoebic liver disease occasionally presents a complication for the anaesthetist. Patients receiving this drug for treatment of amoebic abscess may develop myocardial degeneration with hypotension, tachvcardia, and E.C.G. changes. Congenital syphilis should be looked for-large doses of penicillin given as treatment for or as prophylaxis against a dental infection may induce a Herxheimer reaction.

It is therefore desirable that nonEuropeans should have the following investigations before general anaesthesia: (1) a careful history and clinical examination; (2) haemoglobin estimation; (3) sickle-cell test for patients of African descent (a rapid screening test can be carried out with Sickledex, from Ortho Ltd.); (4) erythrocyte sedimentation rate to detect chronic inflammatory diseases where a satisfactory history is difficult to obtain; (5) chest $x$-ray if there is any question of respiratory disease.

Patients known to have homozygous sickle-cell anaemia should receive a general anaesthetic only as a last resort. Those with a sickle-cell trait will probably come to no harm, so long as hypoxia is avoided. 